\title{
Universitas Lafran Pane
}

Shohibul Anshor Siregar

|Dalam pikiran saya, kampus Lafran Pane berdiri tidak mesti di Sumatera Utara, meski jika disepakati memang lebih bagus di sekitar tanah kelahirannya. Ini sekaligus menjadi jawaban kecil atas kesenjangan regional yang seolah tak memiliki solusi yang jelas

Sepanjang pemberitaan yang saya ikuti, Seminar Nasional Pengusulan Lafran Pane sebagai Pahlawan Nasional tanggal 21 Nopember 2015 di Medan adalah kegiatan lanjutan dari Seminar-seminar yang sama di beberapa kampus-kampus Pulau Jawa. Tanggal 10 Nopember 2015, tepat pada perayaan Hari Pahlawan, diselenggarakan di kampus UII (Yogjakarta).

Salah seorang dari pembicara ialah Hariqo Wibawa Satria, mahasiswa bimbingan Prof.Dr H Agussalim Sitompul, Guru besar perbandingan Agama IAIN Suka (yang sering juga disebut sebagai pustaka berjalan Himpunan Mahasiswa Islam (HMI) karena talent dhabit shadran dan dhabit kitaban yang dimilikinya, teristimewa tentang sejarah HMI). Hariqo Wibawa Satria menulis skripsi tentang sejarah hidup dan perjuangan Lafran Pane pada tahun 2009 lalu. Seminar berikutnya dilaksanakan tanggal 11 Nopember 2015 di kampus tempat Lafran Pane pernah mengajar dan beroleh jabatan guru besar (UNY, Yogjakarta), dengan pembicara Prof Dr Dochak Latief, Dr.Ir.Akbar Tandjung dan Prof.Dr.Syafri Sairin.

Tulisan ini bermaksud menggugah HMI dan KAHMI untuk memilih sebuah bentuk yang saya nilai paling tepat untuk apresiasi dan pengabadian nama Lafran Pane dalam sejarah. Uraian-uraian awal saya maksudkan untuk menunjukkan sikap dan penghargaan saya pribadi terhadap sosok pejuang besar bermarga Pane ini berikut organisasi besar yang didirikannya.

\section{Pendiri HMI}

Lafran Pane memiliki tanggal lahir (1922) yang bersamaan dengan tanggal kelahiran HMI (1947), yakni pada tanggal 5 Februari. Memang belakangan ada sedikit kontroversi di sini. Sebenarnya, menurut Agussalim Sitompul (1976), Lafran Pane lahir di Padangsidimpuan (bukan di Pangurabaan) pada tanggal 5 Februari 1922. Namun untuk menghindari berbagai macam tafsiran, karena bertepatan dengan tanggal berdirinya HMI, Lafran Pane mengubah tanggal lahirnya menjadi 12 April 1923. Kiranya keterangan orang yang sangat dekat dengan Lafran Pane ini dapat sangat dipercaya dan bagi HMI tidaklah menjadi soal untuk menerima kenyataan bahwa HMI berdiri pada tanggal yang sama dengan tanggal lahir pendirinya.

Keluarga Lafran Pane berasal dari sebuah kampung kecil bernama Pagurabaan, Kecamatan Sipirok (sekitar 5-6 km dari kota Sipirok ke arah Utara). la adalah anak keenam dari seorang tokoh terkenal (politisi, saterawan, novelis) bernama Sutan Pangurabaan Pane, yang tulisan-tulisannya banyak mendorong kemajuan rakyat terutama dalam masa transisi. Ompung (kakeknya) adalah seorang ulama bernama Syekh Badurrahman Pane. 
Dua abang kandungnya, Armin Pane dan Sanusi Pane, adalah sasterawan terkenal. Atas saran kedua abangnya inilah kemudian pada tahun 1946 Lafran Pane pindah ke Yogyakarta untuk kuliah. Pilihannya adalah STI (Sekolah Tinggi Islam) yang menjadi cikal-bakal UII (Universitas Islam Indonesia). Sebelum tamat dari STI, Lafran pindah ke Akademi Ilmu Politik (AIP) pada bulan April 1948 yang nanti digabungkan ke dalam Universitas Gajah Mada (UGM) di bawah fakultas Hukum, ekonomi, sosial politik (HESP). Menurut beberapa catatan, Lafran Pane yang meraih gelar sarjananya pada tanggal 26 januari 1953 ini adalah Sarjana Ilmu Politik pertama di Indonesia.

Dalam menjawab tantangan perjuangan mempertahankan kemerdekaan dan memajukan Indonesia, Lafran Pane mungkin sangat terinspirasi oleh sepak-terjang pergerakan yang tercatat pada era sebelumnya, baik di dalam maupun di luar Indonesia. Untuk sekadar menyebut beberapa contoh, Jong IslamittenBond (JIB) yang berdiri tahun 1925 dan Studente Islamitten Studiclub (SIS) yang berdiri tahun 1934 adalah dua organisasi penting untuk pewadahan intelektual muda Islam sebelum HMI berdiri.

Meski tercatat sejumlah nama yang memiliki andil dalam proses berdirinya Himpunan Mahasiswa Islam (HMI) pada tanggal 5 Februari 1947, namun umumnya orang mengakui peran dominan Lafran Pane yang karena itu lazim dianggap pas menjulukinya sebagai pendiri HMI dengan atau tanpa menyebut beberapa nama lain. Dalam sebuah artikel yang ditulis oleh Sujoko Prasodjo pada majalah Media (no 7 Thn III Februari 1957) misalnya, sebuah pengakuan ditegaskan demikian: “...Karena dialah (Lafran Pane, pen) yang punya andil terbanyak pada mula kelahiran HMI, kalau tidak boleh kita katakan sebagai tokoh pendiri utamanya". Pendapat ini dianut oleh mayoritas anggota HMI dan mantan anggota (KAHMI).

Demikianlah, bahwa pada sebuah rapat yang kemudian ditetapkan sebagai hari kelahiran HMI, Lafran Pane sebagai pemrakarsa ada bersama Karnoto Zarkasyi, Dahlan Husein, Maisaroh Hilal, Suwali, Yusdi Ghozali, Mansyur, Siti Zainh, Muhammad Anwar, Hasan Basri, Zulkarnaen, Tayeb Razak, oha Mashudi, dan Bidron Hadi. Keputusan rapat ini pun menetapkan kepengurusan pertama dengan pengamanahan jabatan Ketua kepada Lafran Pane. Asmin Nasution pada posisi Wakil Ketua, Anton Timur Djailani sebagai Penulis I, Karnoto Zarkasyi Penulis II, Dahlan Husein Bendahara I, Maisaroh Hilal Bendahara II, dengan anggota-anggota terdiri dari Suwali, Yusdi Gozali dan Mansyur. Beberapa di antara nama-nama itu juga terkait dengan sejarah awal organisasi-organisasi lain yang lahir berdekatan masa dengan HMI.

Pahlawan Nasional. Lafran Pane, sebagaimana tercermin dari karakter dan cita-cita luhur HMI, kata Prof Dr Syafri Sairin, MA, memang mengupayakan agar Islam menjadi tuan rumah di negeri sendiri. Menginginkan agar Islam dapat menjadi kaum yang intelek, agamis, dan ilmiah, sejajar dengan kaum bangsawan sebagaimana dapat disebut menjadi sebuah masalah besar pada era awal kemerdekaan. Bagi Akbar Tandjung, sebagaimana dikemukakannya pada Seminar di UNY, pendirian HMI adalah proses yang didorong oleh tujuan untuk mempertahankan NKRI, mengangkat derajat rakyat Indonesia serta mengembangkan ajaran Islam di kalangan mahasiswa. 
Banyak yang sudah dicatat oleh sejarah tentang HMI dan Lafran Pane, dan itu menjadi warna kentara melintasi berbagai era sejak orde baru hingga kini, serta terusmenerus berusaha menancapkan paradigma yang sejitu-jitunya untuk menyikapi masa depan Indonesia dan umat Islam sebagai mayoritas. Itu tak boleh berhenti pada status numerical mayority (unggul secara jumlah). Berhenti dalam status mayoritas yang technical minority sesungguhnya adalah derita yang tak memperkenankan adanya kemampuan berkontribusi untuk perbaikan tata dunia serta masalahat seluruh umat.

Indonesia tidak boleh a-historis, tegas Rektor UNY Prof. Dr. Rochmat Wahab, M.Pd., M.A yang melihat rangkaian seminar ini sebagai bagian penting dari pendokumentasikan sejarah. HMI sebagai sebuah almamater besar antar zaman telah melahirkan banyak tokoh penting untuk Indonesia dan bahkan di antaranya tak sedikit yang berkiprah dalam tataran internasional. Rangkaian seminar nasional yang dijadwalkan akan berlangsung selama 18 kali sepanjang akhir tahun 2015 ini adalah sebagai tindak lanjut keputusan Munas HMI yang mengamanahkan agar dilakukan ikhtiyar untuk mengusulkan Lafran Pane menjadi pahlawan nasional.

Apresiasi. Mitologi Yunani sedikitnya memperkenalkan mitos dan legenda mendunia tentang 10 (sepuluh) pahlawan dengan Hercules yang terlalu kuat untuk musuhmusuhnya pada posisi puncak. Achilles, seorang prajurit terbaik pada Perang Troya pada urutan kedua. Selanjutnya Theseus si pahlawan Athena yang membebaskan kotanya dari tirani Raja Minos dari Crete. Lalu ada Odysseus yang adalah salah satu dari sedikit orang Yunani yang mampu mencapai rumah (Ithaca) setelah sepuluh tahun perang dan sepuluh tahun terombang-ambing di laut. Kemudian ada Perseus, Jason, Bellerophon, Orpheus, Cadmus, dan Atalanta, kesemuanya dengan kelebihan masing-masing.

Menurut banyak catatan, Hari Pahlawan dirayakan dengan cara-cara yang berbeda di 18 Negara, yakni Angola, Bahama, Barbados, Cape Verde, Indonesia, Jamaica, Kenya, Mozambique, Namibia,Philipina, Romania, Saint Kitts and Nevis, South Africa, Sri Lanka, Turks and Coicos Islands, Uganda, United Kingdom, Zambia, dan Zimbabwe. Hari Pahlawan atau Hari Pahlawan Nasional, merujuk pada sejumlah peringatan berskala nasional di berbagai negara, adalah sebuah peringatan yang umumnya diselenggarakan pada hari kelahiran pahlawan nasional maupun peringatan peristiwa yang mengantarkan mereka menjadi pahlawan, atau peristiwa penting yang dianggap begitu berpengaruh kepada kehidupan suatu bangsa.

Pendeknya cerita-cerita patriotik akan kita dapatkan dari semua Negara yang memiliki Hari Pahlawan itu, dan jika meihat nama-nama Negara yang memiliki hari pahlawan itu kita dapat berkesimpulan bahwa semua itu adalah sesuatu yang sangat erat kaitannya dengan pembebasan yang meminta pengorbanan, baik nyawa dan harta benda apalagi moral.

Lalu bagaimana cara terbaik mengapresiasi ketokohan dan jasa-jasa seseorang kepada bangsa dan negaranya? Dilihat dari sudut kebangsaan dan kenegaraan, mengukuhkan (oleh Negara) sebagai pahlawan adalah salah satu bentuk apresiasi tertinggi. Lalu apa setelah itu? Ya, tentu ada ziarah yang diagendakan oleh Negara untuk merealisasikan secara formal pandangan "bangsa yang besar adalah bangsa yang menghargai para 
pahlawannya". Jika hanya untuk pola yang berhenti pada apresiasi seperti itu saya kira HMI hendaknya tidak boleh puas terhadap apa yang harus dikenang dari sosok Lafran Pane.

Sekiranya semua berpendapat bahwa HMI adalah sebuah almamater tangguh dan yang sudah teruji oleh sejarah yang di dalamnya proses perkaderan cukup mumpuni untuk menjawab kebutuhan umat dan bangsa, dan karena itu tidak diperlukan sama sekali pewadahan supportif lainnya berupa pelembagaan dalam bentuk kampus, saya kira itu sangat perlu didiskusikan secara serius. Saya mengusulkan HMI bersama KAHMI mendirikan sebuah universitas bernama Lafran Pane. Universitas itu didesain menjadi jawaban untuk masa depan Indonesia, dan jika dilihat dari segi finansial, untuk mendirikan kampus terbesar untuk ukuran Indonesia saat ini, sumberdaya yang dimiliki oleh KAHMI saya nyatakan lebih dari cukup.

Dalam pikiran saya, kampus Lafran Pane berdiri tidak mesti di Sumatera Utara, meski jika disepakati memang lebih bagus di sekitar tanah kelahirannya. Ini sekaligus menjadi jawaban kecil atas kesenjangan regional yang seolah tak memiliki solusi jelas. Semua kita beranggapan bahwa jawaban untuk persiapan generasi mendatang pastilah dengan menunaikan kewajiban mengirim anak ke Jawa sebagaimana dirasakan Lafran Pane pada masa sangat sulit dahulu. Tak sulit menghitung proses pengerdilan daerah yang terus-menerus terjadi dengan budaya keharusan ini.

Universitas terbaik akan selalu dicari oleh semua orang yang berpandangan jauh ke depan. Jika Universitas Lafran Pane memenuhi semua persyaratan kualitatif terbaik untuk menjawab tantangan zamannya dan tantangan masa depan bangsa dan negaranya di tengah persaingan mematikan era global, jadilah ia menjadi jawaban signifikan untuk keluhan dan penderitaan Indonesia kontemporer yang meniscayakan duta-duta muda terbaik tanah air akan bersaing memperebutkan kursi di dalamnya.

Penutup

Melalui tulisan ini saya ingin membujuk dan mendorong Badko $\mathrm{HMI}$ dan KAHMI Sumut agar mengusung gagasan pendirian Universitas Lafran Pane pada Kongres 29 yang akan berlangsung tanggal 1 hingga 5 November 2015 di Pekanbaru. Saya membayangkan bahwa pada salah satu sesi persidangan kongres nanti akan ada acara penyerahan usulan resmi Lafran Pane menjadi Pahlawan Nasional, langsung kepada Presiden Jokowi dan dengan tegas saya berpendapat tidak melalui JK. Sekiranya pun JK yang hadir mewakili Presiden, usulan itu sebaiknya tidak diserahkan kepada beliau. Wapres JK diminta saja mengegendakan pertemuan PB HMI hasil Kongres 29 dengan Presiden RI yang salah satu agendanya penyerahan usulan Lafran Pane Pahlawan Nasional.

Sesi penting lainnya dalam kongres saya bayangkan diberi judul acara "urgensi pendirian Universitas Lafran Pane". Karena itu saya amat berharap pula bahwa Seminar Nasional Pengusulan Lafran Pane sebagai Pahlawan Nasional tanggal 21 Nopember 2015 di Medan akan memberi alokasi perhatian yang cukup tentang gagasan ini. 
Mungkin Prof Dr $\mathrm{H}$ Usman Pelly,MA dan Dr Budi Agustono mengawalinya dalam paparan mereka sebagai narasumber dan meminta dibentuk sebuah tim yang akan mempersiapkan segala sesuatu yang diperlukan untuk dibawa ke Kongres 29. Sekiranya Prof Dr H Syawal Gultom, MPd bekenan, saya pandang ia sangat layak diberi amanah memimpin tim ini, dibantu oleh wakil dari Badko dan Kahmi Sumut serta PB HMI dan Kahmi Pusat.

Shohibul Anshor Siregar Naskah ini pertamakali diterbitkan oleh Harian Waspada Medan, Sabtu, 21 Nopember 2015, hlm B 10 